\title{
Childhood trauma and resilience in old age: applying a context model of resilience to a sample of former indentured child laborers
}

\author{
Andreas Maercker*, Peter Hilpert and Andrea Burri \\ Department of Psychology, University of Zurich, Zurich, Switzerland \\ (Received 4 August 2014; accepted 18 March 2015)
}

\begin{abstract}
Objectives: Psychological resilience has been rarely investigated in elderly populations. We applied a more comprehensive model of trauma-specific coping and resilience, which included Ungar's context model and included decentral factors of resilience (i.e., environments that provide resources to build resilience).

Method: We assessed resilience in a cohort of former Swiss indentured child laborers ( $N=74 ; 59 \%$ males) at two time points; first at the mean age of 80 years and then again 20 months later. At each time point, the following measures of resilience were assessed: resilience indicators of life satisfaction and lack of depression. In addition, resilience predictors of trauma exposure, perceived social support, dysfunctional disclosure of traumatic experiences, social acknowledgment as a victim, and selfefficacy; and decentral resilience factors of education, income, number of children, and physical health were measured.

Results: Using path-analysis, we found that life satisfaction and lack of depression were predicted by dysfunctional disclosure, social support, and self-efficacy at various significance levels. Change scores of resilience were predicted by higher trauma exposure, social acknowledgment as a victim, and an interaction between the two. The model for decentral factors also fitted, with physical health and income predicting the resilience indicators.

Conclusion: Applying this comprehensive resilience model in a sample of older adults revealed meaningful findings in predicting resilience at a single time point and over time. Atypical coping strategies, such as perceived social acknowledgment as a victim and disclosure, may be particularly important for former victims who have suffered institutional abuse.
\end{abstract}

Keywords: resilience; stress; trauma; positive psychology; abuse/neglect

Although extensive research has been conducted on lifelong sequelae of aversive or traumatic childhood experiences in older adults (Amir \& Lev-Wiesel, 2003; Landau \& Litwin, 2000; Schnurr, Spiro, Vielhauer, Findler, \& Hamblen, 2002), there is limited knowledge on the prevalence and predictors of psychological resilience in this age group (Beutel, Glaesmer, Wiltink, Marian, \& Brähler, 2010; Pietrzak \& Cook, 2013). Resilience is defined as the ability to adapt well and maintain high levels of psychosocial functioning following exposure to severe or traumatic stress (Bonanno, Westphal, \& Mancini, 2011; Ungar, 2011). There is a consensus among experts that exposure to adverse, severe, or traumatic life events is a precondition for resilience. However, resilience is not simply the absence of psychopathology following such developmental setbacks (Southwick, Litz, Charney, \& Friedman, 2011). Rather, resilient individuals are those who have adapted well in spite of these adversities.

The majority of studies have investigated resilience and its predictors in samples of young and middle-aged adults (e.g., Masten \& Powell, 2003; Southwick et al., 2011). Until recently, there are only few studies that examined resilience and its predictors in a sample of older trauma survivors (Pietrzak \& Cook, 2013; Tran, Glück, \& Lueger-Schuster, 2013). Pietrzak and Cook found that, nearly $70 \%$ of older United States (US) military veterans (mean age 71 years) were identified as psychologically resilient based on a composite index of current psychological distress. After examination of 49 potential resilience predictors, the following were identified as resilience predictors: higher scores of social connectedness (e.g., perceived social support, community integration), more protective psychological characteristics (e.g., purpose in life), a higher likelihood to be married or living with a partner, and lower physical health difficulties. Although this study provided the first insights into potential resilience factors in older adults, no moderator analyses were conducted to examine the interactive effects between levels of traumatic stress and any of the predictors of resilience. In addition, the cognitive status of the veterans was not controlled for. Tran et al. (2013) investigated Austrian World War II survivors (mean age 82 years) using a multi-phase analysis in which $59 \%$ of the sample was defined as resilient by a single measure. This study controlled for the potential cognitive decline in the older people in its analyses.

The current study built upon and extended the work of these previous studies in several ways. First, we utilized Ungar's (2011) social ecological model of resilience. This model highlights aspects of resilience research by applying a set of principles, including complexity, atypicality, and decentrality. Complexity considers variation in time that characterizes resilience. Although one might expect resilience abilities to remain stable over time, experts in resilience research caution, 'not to expect a resilient person, however defined at one point in time, to be doing

*Corresponding author. Email: maercker@psychologie.uzh.ch 
well ... under all imaginable circumstances, or in perpetuity' (Masten \& Powell, 2003, p. 4). Consequently, a single-point assessment should be complemented by also assessing resilience outcomes over a period of time. The principle of atypicality focuses on alternative coping strategies or 'hidden resilience' (Ungar, 2011, p. 8). In the present study, social support and self-efficacy are investigated as rather common coping styles for dealing with hardships in life, while variables from a trauma-specific socio-interpersonal model (described below) serve as atypical coping styles.

The third principle in the social ecological model is termed decentrality. Ungar (2011) defined decentrality as the facilitative environment that enables the individual access to resources, such as school education or community wealth. In the current study, we examined the relevant decentral environments of the family network, financial resources, and education achieved during lifetime. These factors may provide potential resources or buffers for temporary setbacks. For older people, it can be argued that even physical health is a decentral factor that can lead to different resource use; however, Ungar (2011) did not consider physical health in the original model, which was focused on childhood. The differing perception of physical and mental health changes throughout the lifespan is an often described phenomenon, for which investigation in separate trajectories is recommended (Charles \& Carstensen, 2010).

The current study extends the exploratory approach on potential resilience predictors conducted by Pietzak and Cook (2013) to trauma-specific predictors, based on Maercker and Horn's (2013) social-interpersonal framework of research on trauma sequelae. Central to Maercker and Horn's model are disclosure of traumatic experiences and societal acknowledgment as a survivor. Disclosing trauma has been repeatedly demonstrated in experimental and field studies as crucial for the well-being of survivors (Smyth, Pennebaker, \& Arigo, 2012). However, more indepth investigation has revealed that beneficial and dysfunctional disclosure patterns should be distinguished (Ullman, 2011). Dysfunctional disclosure occurs when victims receive negative responses from others or if the listener has an emotional overreaction to the disclosure (Mueller, Moergeli, \& Maercker, 2008). Ullman (2011) reviewed six cross-sectional and three longitudinal studies on sexual assault disclosure and concluded that the extensiveness, timing, and recipients of disclosure were associated with dysfunctional or pathological outcomes. In addition, in a long-term longitudinal study on traumatized former political prisoners, Maercker and Horn (2013) found lack of dysfunctional disclosure to be a strong predictor of the resilient group (in contrast to the chronic, delayed, and recovered post-traumatic stress disorder (PTSD) groups).

Societal acknowledgement represents another central aspect of Maercker and Horn's (2013) model. It represents how trauma survivors perceive societal empathy and understanding, such as awareness that a community has ascribed braveness or dignity to the survivors for what they have suffered. Studies on so-called 'welcome receptions' for military veterans found societal acknowledgement to be a significant predictor of the level of later development of psychopathology (e.g., Koenen, Stellman, Stellman, \& Sommer, 2003). In a review of four studies, Maercker and Horn (2013) further found that a broad range of negative to positive societal acknowledgement as a victim predicted health status in different trauma groups.

As already outlined, two general health-related psychological factors - perceived social support and self-efficacy - are particularly suitable to complement the two more trauma-specific variables in predicting resilience after childhood adversities and trauma. Social support has been repeatedly shown to be a prime predictor of levels of post-traumatic stress symptoms (e.g., Brewin, Andrews, \& Valentine, 2000). Furthermore, existing longitudinal studies indicate that self-efficacy is likely to mediate the effect of traumatic stress on subsequent psychopathology (e.g., Simmen-Janevska, Brandstatter, \& Maercker, 2012).

In addition to examining a more extensive model of resilience, the goal of this study was to extend existing knowledge on resilience in old age. Individuals in this sample were former indentured child laborers who experienced harsh living conditions and a high probability of aversive or traumatic events. Previous historical and psychological research has shown that these former indentured child laborers have experienced high levels of aversive stress and traumatic exposure (i.e., physical, sexual violence, and high mortality rates of fellow child laborers during forced labor) (Furrer, Heiniger, Huonker, Jenzer, \& Praz, 2014; Schoch, Tuggener, \& Wehrli, 1989); yet, more than half of them did not develop psychopathology in old age (Kuhlman, Maercker, Bachem, Simmen-Janevska, \& Burri, 2013; Maercker, Krammer, \& Simmen-Janevska, 2014).

In our conceptual model, we assumed that four factors predicted well-being and lack of depression: trauma exposure, resilience predictors (e.g., social support), the interaction between trauma exposure and resilience predictors, and the decentralized resilience factors (see Figure 1). We also assumed that these factors predicted how well-being and depression changed over time. Based on the existing literature on trauma sequelae, resilience, and its predictors, we formulated the following hypotheses: (1) trauma exposure as well as typical and atypical coping factors predicts both level and progression of resilience indicators (i.e., life satisfaction and lack of depression); (2) atypical resilience predictors (e.g., disclosure of the trauma, social acknowledgement as victim) may not only influence the resilience indicators directly, but also moderate the association between trauma exposure and resilience indicators; (3) based on the decentrality postulate of Ungar's resilience model, we assume that higher level of education, better financial resources, more children, and better physical health predict higher levels of life satisfaction and less depression.

\section{Materials and methods Sample}

The study sample was drawn from a historically unique cohort of former Swiss indentured child laborers (i.e., 


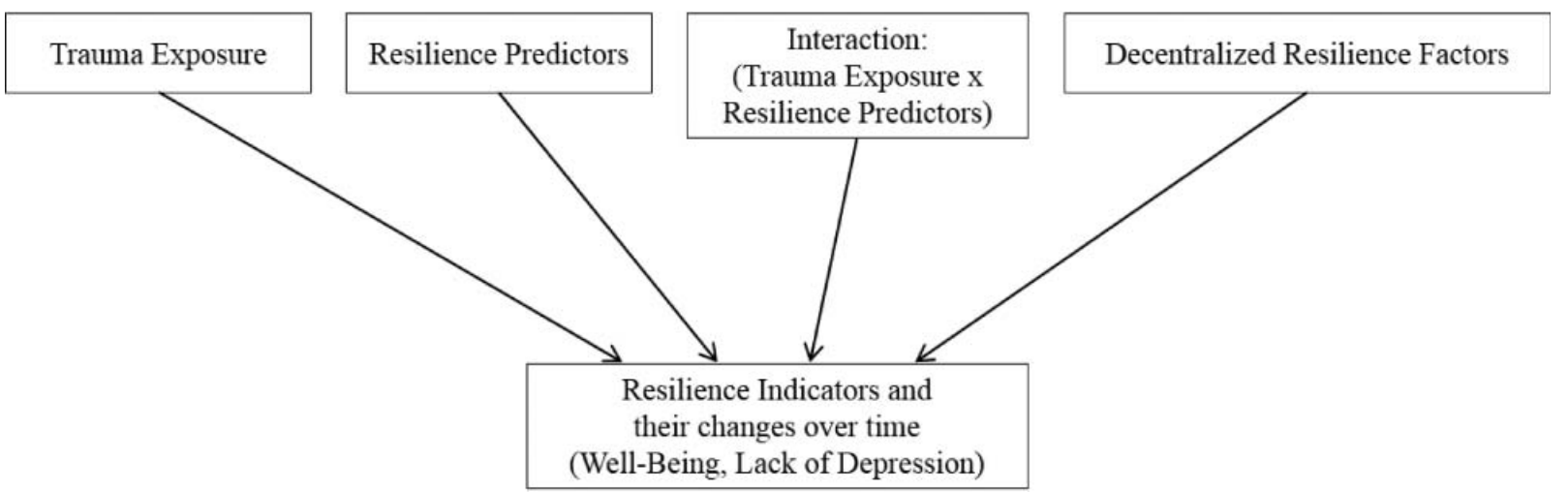

Figure 1. Conceptual model depicting the assumption that resilience indicators (i.e., well-being and lack of depression) and their changes over time is predicted by (1) trauma exposure, (2) resilience predictors (e.g., social support), (3) the interaction between trauma exposure and resilience predictors, and (4) decentral resilience factors.

Verdingkinder). Until the 1960s, these children were removed from their parents by the Swiss authorities and sent to work on farms. Historic studies have shown that many of these children suffered extreme forms of abuse, as they were regularly beaten, emotionally and sexually abused (Leuenberger \& Seglias, 2008; Maercker et al., 2014). Reasons for the separation from their biological family were the violation of Swiss social norms including, single motherhood (even in case of widowhood), alcoholism of a parent, being of gipsy origin, and presumed poverty of the parents. On a socio-economic macrolevel, there was a need for cheap labor in some Swiss farming communities. Children were forced into indentured labor beginning at an age 4 or 5 years and usually had to change their place of work several times until reaching official adulthood age. They did not receive payment for their work. They often were unable to marry because they lacked financial resources and experienced other related setbacks during their lifespan. On 11 April 2013, approximately 50 years after the child labor laws were abolished, the Swiss Government issued a formal apology for the former legal wrong.

\section{Recruitment and design}

The present study was part of a larger project on trauma aftermath and psychological processes in indentured child laborers, with particular emphasis on PTSD, complex PTSD, and late-life depression (see Maercker, Krammer \& Simmen-Janevska, 2014; Burri, Maercker, Krammer, \& Simmen-Janevska, 2013). Initial recruitment of participants and the cross-sectional data collection took place between 2010 and 2012; this was considered the baseline time point for the present study (T1). Though the initial trial was not intended to be longitudinal, in 2012, the participants were invited for a follow-up assessment (T2). Therefore, the study does not constitute a 'common' longitudinal design, which explains the comparably high attrition rate (see below). Both data collection waves were approved by the University of Zurich's Institutional Review Board and Ethics Committee (KEK-ZH 2010/ 2012-0245).
To be included in the study, the following criteria had to be met: Swiss-German speaking; a minimum age of 60 years; and at least one experienced period of indentured child laboring. Participation in the study was completely voluntary. Participants were recruited via advertisements in magazines and newspapers throughout Switzerland. Participants who were interested in participating contacted the research team directly by phone or email. All participants provided informed consent and stated their willingness to participate in this study. After providing written informed consent, subjects participated in a two to three hour structured interview and were asked to fill in a battery of questionnaires assessing information related to PTSD, trauma, and a number of variables of interest (i.e., cognitive functioning, physical and mental health, psychopathologies, etc.). The interview was conducted by instructed research assistants and/or doctoral students, either in the experimental rooms at the University of Zurich or alternatively at the participants' homes.

As mentioned before, the unannounced re-invitation of the study participants lead to a comparably high attrition rate. At T1, data were available for 140 participants and at T2 for 74 . Twelve percent $(n=17)$ of the T1 sample could not be contacted or be re-invited due to death or unknown residence. Thus, the attrition rate of individuals contacted was $35.1 \%$. Table 1 provides an overview about the demographics of the final sample $(N=74)$.

\section{Materials}

A set of standardized and validated questionnaires, and study-specific questions were used to assess the variables of interest.

\section{Trauma exposure}

The World Health Organization's Composite International Diagnostic Interview Score (CIDI; Wittchen, Lachner, Wunderlich, \& Pfister, 1998) and the Childhood Trauma Questionnaire (CTQ; Bernstein \& Fink, 1998) were used to assess trauma exposure. A composite score of the two questionnaires, computed by adding the full 
Table 1. Demographic characteristics of sample $(N=74)$.

\begin{tabular}{lccc}
\hline & Mean & SD & Range \\
\hline Age (years) & 80.0 & $(6.8)$ & $61-101$ \\
Age indentured (years) & 5.86 & $(4.3)$ & $1-16$ \\
Duration indentured (years) & 10.6 & $(5.06)$ & $1-26$ \\
Education (years) & 10.4 & $(2.8)$ & $4-22.5$ \\
Physical health (SF-12) & 42.5 & $(11.6)$ & $13-58$ \\
Mental health (SF-12) & 48.8 & $(10.5)$ & $18-69$ \\
& & & \\
Financial status (income) & & & \\
$\quad$ Too little (<25,000 SF/a) & 18.0 & $(13.0)$ & \\
$\quad$ Moderate (<50,000 SF/a) & 39.0 & $(28.3)$ & \\
$\quad$ Good (<75,000 SF/a) & 53.0 & $(38.4)$ & \\
$\quad$ Very good (>75,000 SF/a) & 28.0 & $(20.3)$ & \\
& & & \\
Current marital status & & & \\
$\quad$ Never married & 9.0 & $(6.4)$ & \\
$\quad$ Married & 98.0 & $(80.0)$ & \\
Living apart/divorced & 31.0 & $(22.1)$ & \\
$\quad$ Widowed & 2.0 & $(1.4)$ & \\
Number of children & & & \\
0 & 17 & $(23.0)$ \\
1 or more & 57 & $(77.0)$ & \\
\hline
\end{tabular}

scores, was used to represent the level of lifetime traumatization. This score we labeled as CTQ-CIDI.

The 28-item CTQ assesses retrospective reports of childhood maltreatment (Bernstein et al., 2003). It assesses five domains: emotional abuse, physical abuse, sexual abuse, emotional neglect, and physical neglect. Emotional abuse refers to verbal assaults on a child's sense of worth or well-being, or any humiliating, demeaning, or threatening behavior directed toward a child by an older person. Physical abuse refers to bodily assaults on a child by an older person that pose a risk of, or result in, injury. Sexual abuse refers to sexual contact or conduct between a child and an older person, including explicit coercion. Emotional neglect refers to the failure of caretakers to provide basic psychological and emotional needs, such as love, encouragement, belonging, and support. Physical neglect refers to failure to provide basic physical needs, including, food, shelter, and safety. Each item begins with 'When I was growing up...' and proceeds to identify experiences pertaining to the childhood rearing environment. The participants rated their responses on the scale's original five-point Likert scale. The conventional CTQ total score was high in the current sample with a Cronbach's alpha of .88. The CTQ has been extensively validated in adult samples and is considered to be a reliable measure of childhood maltreatment exposure (Fergusson, Horwood, \& Boden, 2011). For the purpose of creating the CTQ-CIDI score, the subscores were dichotomized into ' 1 ' (above threshold) or ' 0 ' (below threshold) following the thresholds reported by Tietjen et al. (2010).

In addition to the CTQ, the CIDI (Wittchen et al., 1998) was applied, allowing the collection of comprehensive data on lifetime trauma exposure in 13 categories of life events. If a category was endorsed, it was counted as ' 1 ' for adding to the comprehensive CTQCIDI score. The composite lifetime trauma score CTQCIDI had a range from 0 to 18 .

\section{Resilience predictors}

Perceived social support was measured by a 14-item short version of the widely used German Social Support Questionnaire (SSQ; Fydrich, Sommer, Menzel, \& Höll, 1987; Fydrich, Sommer, Tydecks, \& Brähler, 2009). The questionnaire produces a composite score that reflects an individual's perceived emotional (e.g., 'I have friends or family members who listen to me when I want to talk about a problem') and practical support (e.g., 'I can borrow anything I need from friends or neighbors'), as well as perception of social integration (e.g., 'There is a group of people to whom I belong to and with whom I meet regularly'). A five-point Likert scale is used on the SSQ. Previous validation studies have reported good psychometric properties. Internal consistency in the present sample was high with Cronbach's $\alpha=.87$.

The General Self-Efficacy (GSE) scale was used to assess the 'broad and stable sense of personal competence to deal effectively with a variety of stressful situations' (Scholz, Gutierrez Dona, Sud, \& Schwarzer, 2002, p. 243). The GSE was based on Bandura's (1977) concept of selfefficacy. Participants rated 10 items (e.g., 'I am confident that I could deal efficiently with unexpected events') on a four-point Likert scale. The internal consistency of this questionnaire subscale in the present study was $\alpha=0.91$.

The German, 16-item 'Social Acknowledgment Questionnaire' (SAQ; Maercker \& Müller, 2004) was used to assess the traumatized individual's perception of his or her recognition as a victim or as survivor and of his or her support from family, friends, acquaintances, and local authorities. The questionnaire consists of the three subscales 'Recognition', 'General disapproval', and 'Family disapproval.' A total score is usually computed. Response options were on a four-point Likert scale, ranging from 'not at all' (1) to 'completely' (4). Questions include examples like, 'most people cannot understand, what I went through' (inversely coded). The initial validation on $N=329$ individuals with and without traumatization showed good reliability ( $\alpha$ ranging from .79 to .86 ) and high test-retest reliability over 2 months ( $\alpha=.74$ to .85 ). Cronbach's $\alpha$ of the total score in the present study was $\alpha=.77$.

The Disclosure of Trauma Questionnaire (DTQ) was used in an abbreviated version to assess three key dimensions of the participants' attitudes and intentions to disclose potential trauma to others, including: Reluctance to talk (four items), Urge to talk (four items), and Emotional reactions during disclosing (four items) (Müller, Beauducel, Raschka, \& Maercker, 2000). Items were rated on a six-point scale, ranging from 'Not at all' (0) to 'Completely' (5). Furthermore, a total disclosure score can be computed, with higher score representing higher levels of dysfunctional disclosure. In the present study, Cronbach's $\alpha=.83$. 


\section{Resilience indicators}

In the present study, two indicators of resilience were used, including lack of depressive symptoms and life satisfaction. For both variables, a single-point measure (T1) and a progression index (T2-T1) across 20 months were used.

Assessment of satisfaction with life was conducted using a single question: 'How satisfied are you at present with your life in general?', using a Likert-type five-point response format (from 'not at all' to 'markedly'). This single-item assessment has been previously introduced by Campbell, Converse, and Rodgers (1976) and has been widely applied. Its external validity with regard to multiitem assessments has been repeatedly established (Lucas \& Donnellan, 2012; Yohannes, Dodd, Morris, \& Webb, 2011).

The Geriatric Depression Scale (GDS) has been introduced as a reversed indicator for life satisfaction in many studies (Coleman, Philp, \& Mullee, 1995; Loke, Abdullah, Chai, Hamid, \& Yahaya, 2011). The GDS is a 15item self-report instrument specifically designed to identify depression in older people (Sheikh \&Yesavage, 1986). Questions were answered in a 'yes' or 'no' format, which enables the scale to be used with severely or moderately cognitively impaired individuals. The higher the GDS score, the more the depression symptoms are. Validation studies of the German version of the GDS found the scale to be a reliable and valid screening instrument. In the present study, a Cronbach's alpha of .81 was found.

\section{Decentral resilience factors}

Information on educational lifetime achievement, current financial status (household income), and number of children were collected with self-constructed questions. Functional health and level of impairment caused by either physical or emotional conditions were assessed with the generic SF-12 (Short-Form Health Survey) (Ware, Kosinski, \& Keller, 1996). Response options were on a yes/no scale, and the total score was obtained by summing the questionnaire items, with higher values reflecting better and less impaired health. The SF-12 leads to the summary score of physical health (the mental health is not considered for the current study). Cronbach's $\alpha$ in this study was $\alpha=0.70$.

\section{Potential confounder}

Cognitive impairment was assessed with the Structured Interview for Diagnosis of Dementia of Alzheimer Type, Multi-infarct Dementia and Dementia of other Etiology according to ICD-10 and DSM-III-R (SIDAM; Zaudig et al., 1991). The SIDAM test performance part consists of a range of cognitive tests that constitute a neuropsychological battery with 55 questions and which yield a maximum score of 55, with higher values indicating better cognitive functioning. In the current study, reliability coefficient was $\alpha=0.78$ for the total SIDAM (called SISCO) score.

\section{Statistical analyses}

Hypotheses 1 and 2 were tested with path-analytical modeling. This approach allows simultaneous analysis of the associations between the independent variables (trauma, four resilience predictors, and their interactions) and the dependent variables at $\mathrm{T} 1$ and their progression index (T2-T1), as depicted in Figure 2. To control for cognitive impairment, the SIDAM score was also included in the model. Due to restrictions arising from the relatively small sample size, given the model complexity,

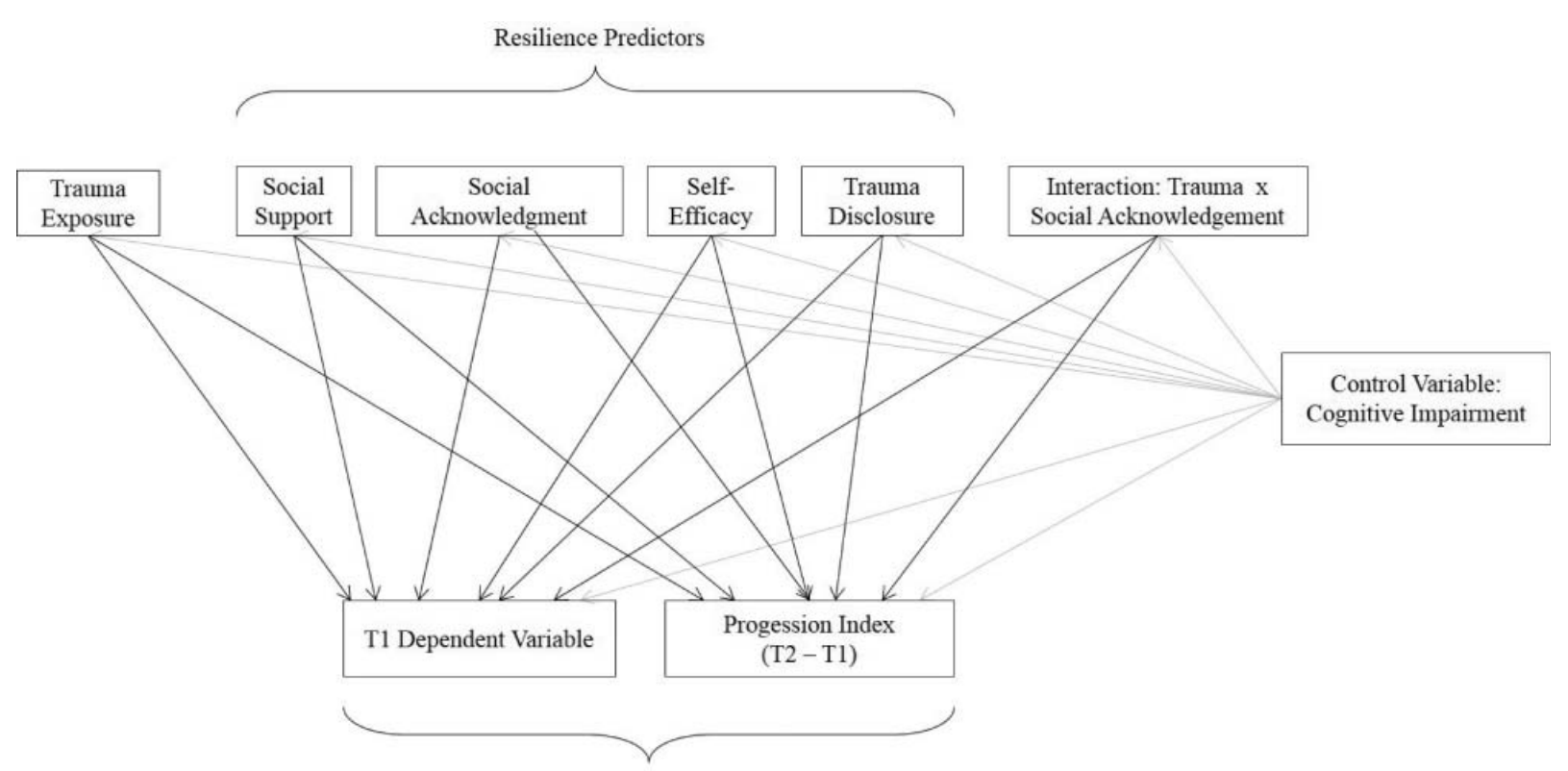

Resilience Indicator: Life Satisfaction (Model 1); Depression (Model 2)

Figure 2. Trauma exposure, resilience predictors, and interactions between them predict the resilience indicators at Time 1 and the progression index 20 months later. Because of sample size restrictions, one model was specified for the resilience indicator depression and one for life satisfaction. 
analyses were run separately for the dependent variables of life satisfaction and depression. For both models, a stepwise procedure was adopted. First, we computed the progression index for life satisfaction and depression by subtracting T1 from T2. In the second step, the independent variables were centered and interaction terms were computed using the centered variables. In the third step, all centered independent variables and their interaction terms were included in the models. In order to reduce model complexity, we removed the interaction terms which were not significant in the fourth step. Finally, theory-driven restrictions were included in the model.

Because of the aforementioned sample size restrictions, hypothesis 3 was tested in an additional path-analytical model (see Figure 3). The decentral factors (education, income, number of children, and physical health) were synchronous predicting the two resilience indicators life satisfaction and lack of depression. In order to achieve a parsimonious model, non-significant paths were excluded from this model.

To assess the model fit, we relied on common fit indices for structural equation modeling (Schermelleh-Engel, Moosbrugger, \& Mueller, 2003): $\chi^{2}$-value for absolute model fit, comparative fit index (CFI) and Tucker Lewis index (TLI) for relative model fit, and root mean square error of approximation (RMSEA) for closeness of fit. We used SPSS 22 for descriptives and MPlus 7.1 (Muthén \& Muthén, 1998-2014) for the path models, applying the robust maximum likelihood estimator (MLR). To handle missing data, we applied the full information maximum likelihood estimator (FIML; Graham, 2003, 2009).

\section{Results}

\section{Descriptive statistics}

Table 2 displays the means and standard deviations of variables used in this study. Based on traumatization in

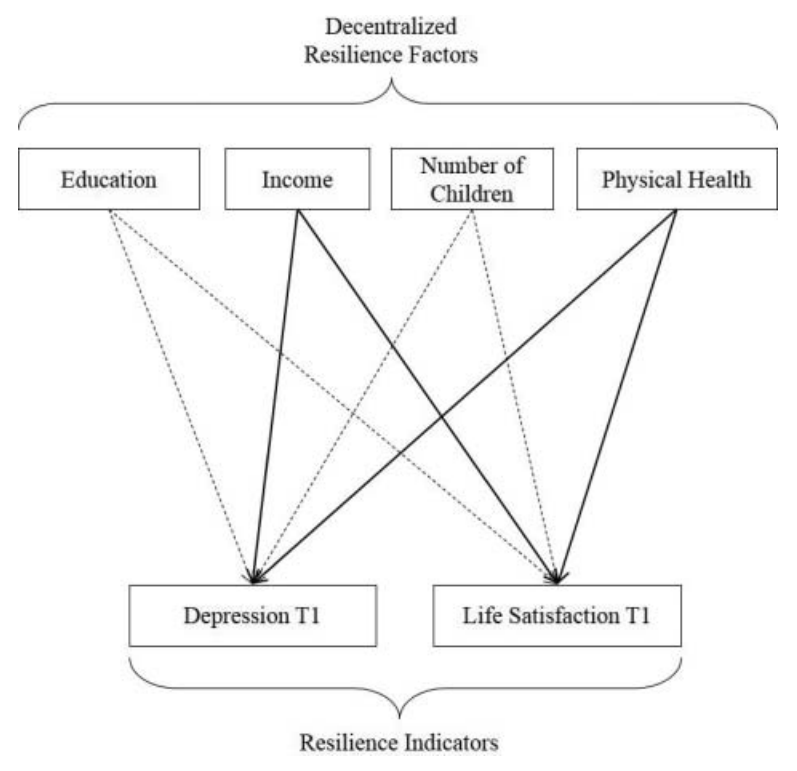

Figure 3. Model 2. Decentral resilience factors predicting resilience indicators at Time 1 (significant paths in bold). childhood, results indicated an average CTQ traumatization score of 61.8 , indicating high psychological strain compared to, for example, clinical groups in a German study on adults traumatized in childhood (Wingenfeld et al., 2010). On average, participants reported 2.6 traumas out of a maximum of 13 adulthood trauma categories from the CIDI. Based on the resilience factors, we found that our sample had a lower mean value for social support (Fydrich et al., 2009), and lower levels of social acknowledgment (e.g., Maercker \& Horn, 2013). We found higher values of dysfunctional disclosure (Müller \& Maercker, 2006) and mid-size levels of self-efficacy compared to population samples (e.g., Scholz et al., 2002). For the resilience indicators, study participants showed a relatively high level of life satisfaction (mean $=3.8$, range $1-5$ ) and a relatively low level of depressive symptoms (mean $=2.7$, range $0-14)$ as in a comparible population studies (Djemes, 2006).

Table 3 presents the intercorrelations among all study variables. Childhood trauma experience was negatively associated with depressive symptoms and with social acknowledgement, but correlated positively with dysfunctional disclosure as well as subjective life satisfaction.

\section{Path-analytical findings}

In hypotheses 1 and 2, we tested whether the comprehensive trauma score, the four resilience predictors and/or the interaction between childhood trauma and resilience factors might predict resilience or the change of resilience over time. The control variable of cognitive impairment had no significant effect on any of the variables in the models.

Life satisfaction. Overall, the path-analytical model fit the data well $\left(\chi^{2}=0.1 ; d f=1 ; p=0.77 ; \mathrm{CFI}=1.00\right.$; $\mathrm{TLI}=1.38$; RMSEA $=0.00)$. The frequency of lifetime traumas was unrelated to the level of life satisfaction at $\mathrm{T} 1$, but the lifetime trauma score predicted the change of life satisfaction over the course of the 20 months $\left(\beta_{\text {Trauma }}=\right.$ $.07, p=.025)$, indicating that higher levels of trauma are associated with an increase in life satisfaction. Of the four resilience predictors, only dysfunctional disclosure was significantly associated with life satisfaction $\left(\beta_{\text {Support }}=-.02\right.$, $p=.047)$, indicating that more dysfunctional disclosure is associated with a decrease in life satisfaction. In addition, we found a marginally significant association between perceived social support and life satisfaction $\left(\beta_{\text {Disclosure }}=.04\right.$, $p=.058$ ), with more perceived social support predicting more life satisfaction. Overall, none of the interaction terms were significantly associated with life satisfaction or the change in life satisfaction over time.

Lack of depression symptoms. We further tested whether lifetime trauma, the resilience predictors, and/or the interaction between them might be associated with the lack of depressive symptoms or a change of depressive symptomatology over time. Again, the path-analytical model fit the data well $\left(\chi^{2}=0.2 ; d f=1 ; p=0.67\right.$; CFI $=$ $1.00 ; \mathrm{TLI}=1.38$; RMSEA $=0.00)$. Results indicated that the frequency of lifetime trauma was neither predicting the lack of depressive symptoms nor the change of them. From the four resilience predictors, only perceived social 
Table 2. Mean, standard deviation, and range of all path model variables.

\begin{tabular}{lccc}
\hline Variables & Mean & SD & Range \\
\hline Time 1: Trauma exposure & & & \\
Childhood trauma total value (CTQ) & 61.8 & $(12.9)$ & $31-94$ \\
Adulthood trauma (CIDI) & 2.6 & $(3.3)$ & $0-13$ \\
Lifetime trauma, combined CIDI-CTQ & 6.0 & & $1-17$ \\
& & $(5.6)$ & $5-25$ \\
Time 1: Resilience predictors & 17.2 & $(7.4)$ & $-21-11$ \\
Social support & -4.3 & $(12.5)$ & $14-69$ \\
Social acknowledgement as a victim & 33.3 & $(6.1)$ & $13-40$ \\
Dysfunctional disclosure & 30.2 & & $1-5$ \\
Self-efficacy & & $(1.2)$ & $0-14$ \\
& & $(3.6)$ & $22-55$ \\
Time 1: Resilience indicators & 3.7 & $(6.4)$ & $1-5$ \\
Life satisfaction & 3.6 & & $0-14$ \\
Depression (GDS) & 46.3 & $(1.2)$ & $-6-5$ \\
SIDAM score (SISCO)/confounder & & $(3.6)$ & \\
Time 2: Resilience indicators & & & \\
Life satisfaction & 3.8 & $(1.2)$ & \\
Depression (GDS) & 2.7 & $(2.5)$ & \\
Change index (T2 - T1): Resilience indicators & & & \\
Life satisfaction difference & -0.0 & \\
Depression (GDS) difference & -0.3 & & \\
\hline
\end{tabular}

support was significantly associated with depressive symptoms ( $\left.\beta_{\text {Support }}=-.13, p=.026\right)$, with more support predicting less depressive symptoms. In addition, we found two marginally significant direct effects. Both selfefficacy and dysfunctional disclosure were marginally associated with the lack of depressive symptoms $\left(\beta_{\text {Self-efficacy }}=-.10, p=.068 ; \beta_{\text {Dysfunc. disclosure }}=-.06\right.$, $p=.072$ ), indicating that higher self-efficacy and lower dysfunctional disclosure is associated with lack of depression symptoms. Furthermore, the part of the model predicting the changes of depressive symptoms found a surprising result for social acknowledgment. The social acknowledgment of being a victim further predicted the change of depressive symptoms $\left(\beta_{\text {Socialacknowledgment }}=\right.$ $.11, p=.050)$; more social acknowledgment was associated with an increase in depressive symptoms over time. In addition, the interaction term between childhood trauma and social acknowledgment predicted an increase in depressive symptoms over time $(\beta=.03, p=.005)$.

Decentral factors. We predicted that the decentral factors determine life satisfaction and lack of depression. A good model to data fit was found $\left(\chi^{2}=3.0 ; d f=5 ; p=\right.$ $0.70 ; \mathrm{CFI}=1.00 ; \mathrm{TLI}=1.07$; RMSEA $=0.00)$. Results indicated that higher income at T1 was associated with a higher level of life satisfaction $(\beta=.27, p=.019)$ but with a lower level of depression $(\beta=-1.07, p=.001)$.

Table 3. Intercorrelations of the study variables at Time 1 .

\begin{tabular}{|c|c|c|c|c|c|c|c|c|c|c|}
\hline Path model variables & 1 & 2 & 3 & 4 & 5 & 6 & 7 & 8 & 9 & 10 \\
\hline \multicolumn{11}{|l|}{ (1) Lifetime trauma, combined } \\
\hline (2) Social support & -.15 & & & & & & & & & \\
\hline (3) Social acknowledgement as a victim & -.24 & .38 & & & & & & & & \\
\hline (4) Dysfunctional disclosure & .23 & -.29 & -.38 & & & & & & & \\
\hline (5) Self-efficacy & -.14 & .24 & .31 & -.09 & & & & & & \\
\hline (6) Life satisfaction & -.21 & .32 & .25 & -.29 & .16 & & & & & \\
\hline (7) Depressive symptoms & .23 & -.38 & -.37 & .39 & -.29 & -.60 & & & & \\
\hline \multicolumn{11}{|l|}{ Decentral resilience factors } \\
\hline (8) Education achieved & -.10 & .16 & .13 & -.09 & .13 & .09 & -.15 & & & \\
\hline (9) Financial situation (income) & -.23 & .31 & .25 & -.24 & .34 & .27 & -.34 & .22 & & \\
\hline (10) Number of children ( 0 vs. $\geq 1)$ & -.07 & .08 & .04 & -.13 & .07 & .01 & -.10 & -.17 & .03 & \\
\hline (11) Physical health & -.24 & .36 & .36 & -.36 & .24 & .56 & -.59 & .21 & .37 & .01 \\
\hline
\end{tabular}

Note: Significant correlations in bold ( $p<.05$, two tailed). 
Similarly, a higher level of physical health at T1 was associated with a higher level of life satisfaction $(\beta=.03$, $p=.001)$ but with a lower level of depression $(\beta=-.08$, $p=.003)$.

\section{Discussion}

The current study investigated psychological resilience in older people using a sample of individuals who were maltreated or traumatized in their childhood and adolescence. This group of Swiss former indentured child laborers (Verdingkinder) has already been intensively investigated (e.g., Burri et al., 2013; Kuhlman et al., 2013; Maercker et al., 2014). As an exemplar of childhood traumatization, individuals in the Verdingkinder population share some features of childhood institutional abuse with populations from Austria, Ireland, and other European countries. These qualities include harsh regime, childhood labor, and frequent sexual assaults (Carr et al., 2010; LuegerSchuster et al., 2014; Wolfe, Jaffe, Jette, \& Poisson, 2003).

Previous findings on the current sample showed that only a small proportion of the former indentured child laborers suffer from mental disorders as defined by the DSM-IV (e.g., 23\% PTSD, 24\% major depressive disorder, $8 \%$ generalized anxiety disorder; Kuhlman et al., 2013; Maercker et al., 2014). The majority of the participants show indications of resilience, despite having suffered from high amounts of childhood or lifetime trauma or adversities.

Given this observation, our current investigation was based on the social ecological model of resilience (Ungar, 2011) and on its components of complexity (variations in time), atypicality (alternative coping styles), decentrality (current individual features and functional lifetime outcomes). This framework was applied to overcome the shortcomings of previous resilience research in which generally only one resilience outcome - mostly selfreported resilience - was investigated ( $c f$ Ungar, 2011).

Three assumptions were formulated which form the basis for the following discussion of the findings. First, we hypothesized that levels of trauma exposure during lifetime (i.e., childhood adversities or traumas and adult traumas) predict both the current and 20-months change in resilience indicators. The two path-analytical models of life satisfaction and lack of depression showed a good fit to the data and thus allowed differential predictions of the point-in-time and progression score. Thus, a more complex set of resilience indicators $(2$ indicators $\times 2$ timeframes) was meaningfully predicted. As outlined by Ungar (2011), resilience should be measured considering its variability across time and in appearance. Previous resilience research mostly suffers from overconfidence in single resilience indicators, such as the utilization of resilience (short) scales.

Second, we assumed that several resilience predictors such as lifetime trauma, common coping styles (e.g., perceived social support, self-efficacy), and uncommon coping styles (e.g., disclosure of the trauma, social acknowledgement as victim) may not only influence the resilience indicators directly, but also moderate the association between trauma exposure and resilience indicators. Here, a more complex pattern with some surprising associations emerged. Lifetime trauma exposure predicted an increase in life satisfaction at only the 20 -months period (T2) but not for the baseline measurement of resilience (T1). The prediction of increased life satisfaction by higher traumatic exposure may indicate that adjustment processes in old age may benefit from personal experience of traumas and hardships during one's life. Possibly, study participants gained from disclosing their traumatic experiences during the T1 interviews and may therefore have felt better of at T2, which may explain the differential outcomes. It remains to be further investigated in which way traumatic or aversive childhood events are related to psychological resilience at age 80 or whether this finding is due to methodological limitations of our study design (see "Limitation" section below). Pietrzak and Cook (2013) found trauma exposure severity determined membership in the resilient group, but they applied another methodology (group comparison) and their sample was traumatized as veterans around age 20 and assessed at a medium age of 70 years.

Furthermore, an interaction of social acknowledgment as victims and lifetime trauma negatively predicted lack of depression and its progression. This means that more social acknowledgment as a victim is associated with an increase in depressive symptoms over time. One possible explanation for this finding is that acknowledgment of one's suffering very late in life may be too late and contribute to depressive ruminations instead of stress relief. So far, research on social acknowledgment of trauma victims has never investigated elderly populations at age 80 ; therefore, future studies are needed to further investigate this finding (Maercker \& Horn, 2013).

For the other predictors included in the resilience path models, more consistent results were obtained, albeit at various significance levels (significant at $p<.05$ or marginally significant up to $p \leq .072$ ). Social support and self-efficacy, for example, predicted higher levels of resilience at $\mathrm{T} 1$ and $\mathrm{T} 2$, whereas dysfunctional disclosure of traumatic experiences negatively predicted resilience. The contributions of dysfunctional disclosure - and social acknowledgment as a victim - indicate that resilience is not only related to well-known predictors like social support or self-efficacy but also to more atypical styles of coping with previous traumatization (cf Ungar, 2011).

Finally, based on Ungar's (2011) framework model of resilience, we hypothesized that 'decentral' outcomes of resilience are explained by our data. To test this assumption, four functional lifetime resilience outcomes were included: education achieved, financial situation, number of children, and physical health. Although the corresponding path-analytical model fit the data well, only two of the four decentral factors predicated life-satisfaction and depression: physical health and financial situation (or income). The former finding on physical health corroborates findings reported by Pietrzak and Cook (2013). In their study on older US veterans, three predictors (number of medical conditions, instrumental activities, and 
activities of daily living: IADL/ADL) were associated with significant advantages for the resilience group. With regard to financial situation, however, the authors found no significant group differences between the resilient, the distressed, and the control group. Again, sample group (i.e., contextual-historic) differences may explain this incongruence. In their study, the variables of lifetime education achieved and number of children were not significantly predictive of resilience, although higher educational achievements were shown for the resilient group of US veterans (Pietrzak \& Cook, 2013). Oral history accounts of former indentured child laborers have also suggested that many of them deliberately refused to become parents (Furrer et al., 2014; Schoch et al., 1989).

\section{Limitations}

Our results need to be interpreted in view of several limitations. First, for the second data assessment, only $65 \%$ of the surviving participants from $\mathrm{T} 1$ agreed to participate, therefore restricting the statistical power of our analyses. Second, the time interval (T1-T2) was short (an average 20 months) compared to the average age of the participants, which was 80 years. Thus, the time frame to investigate individual resilience in old age remained comparably narrow. However, this is the first study investigating resilience in a sample of older people including a longitudinal aspect. Third, the majority of variables included in the analyses relied on self-report, which is known to be of restricted reliability and validity particularly if a long period of one's life had to be self-rated. Exceptions here were some of our functional resilience outcomes (lifetime achievement, current household income, and number of children) and the confounder assessment of cognitive decline that were objective data or assessed by interviewers. Fourth, the trauma exposure score was a composite score from two independent measures, the CTQ (with post hoc dichotomization) and the CIDI (with original dichotomization). The combination of these two measures can be justified with regard to content, but presently lacks an independent psychometric validation. In the current study, power reasons for path analysis were an additional reason to apply this composite score. Fifth, a more general limitation concerns the adequacy of the study design to test/verify the social ecology model of resilience (Ungar, 2011). This framework model has previously been applied only to children or adolescent samples. Here, the model was extended to a group of older people of around 80 years with a time interval of around 70 years between data assessment and the actual traumatization. Therefore, the adequacy of Ungar's (2011) theory for investigating a sample of older individuals cannot yet be decided. One advantage of the study, however, is that the path-analytical models of resilience predictions controlled for cognitive status by using state-of-the-art gerontological assessment instruments.

\section{Conclusion}

Taken together, the study extends the scarce empirical literature on resilience in older people who were traumatized as youth. We propose that an application of a more elaborated framework of resilience research, such as the social ecological model by Ungar (2011), may lead to an improved conceptual and empirical base to study resilience. However, we acknowledge that parts of our findings are still inconsistent or fragmentary and more systematic investigation of this important area of research is needed in future studies.

\section{Disclosure statement}

No potential conflict of interest was reported by the authors.

\section{Funding}

Parts of the study (Time 1 assessment) were supported by a grant from the Swiss National Science Foundation [SNF 100014_124535].

\section{References}

Amir, M., \& Lev-Wiesel, R. (2003). Time does not heal all wounds: Quality of life and psychological distress of people who survived the Holocaust as children 55 years later. Journal of Traumatic Stress, 16(3), 295-299.

Bandura, A. (1977). Self-efficacy: Toward a unifying theory of behavioral change. Psychological Review, 84(2), 191-215. doi:10.1037/0033-295X.84.2.191

Bernstein, D.P., \& Fink, L. (1998). Childhood trauma questionnaire. A retrospective self-report. Manual. San Antonio, TX: Harcourt.

Beutel, M.E., Glaesmer, H., Wiltink, J., Marian, H., \& Brähler, E. (2010). Life satisfaction, anxiety, depression and resilience across the life span of men. The Aging Male, 13(1), $32-39$.

Bonanno, G.A., Westphal, M., \& Mancini, A.D. (2011). Resilience to loss and potential trauma. Annual Review of Clinical Psychology, 7, 511-535. doi:10.1146/annurevclinpsy032210-104526

Brewin, C.R., Andrews, B., \& Valentine, J.D. (2000). Meta-analysis of risk factors for posttraumatic stress disorder in trauma-exposed adults. Journal of Consulting and Clinical Psychology, 68(5), 748-766.

Burri, A., Maercker, A., Krammer, S., \& Simmen-Janevska, K. (2013). Childhood trauma and PTSD symptoms increase the risk of cognitive impairment in a sample of former indentured child laborers in old age. PloS One, 8(2), e57826.

Campbell, A., Converse, P.E., \& Rodgers, W.L. (1976). The quality of American life: Perceptions, evaluations, and satisfactions (Vol. 3508). New York, NY: Russell Sage.

Carr, A., Dooley, B., Fitzpatrick, M., Flanagan, E., FlanaganHoward, R., Tierney, K., ... Egan, J. (2010). Adult adjustment of survivors of institutional child abuse in Ireland. Child Abuse and Neglect, 34(7), 477-489.

Charles, S., \& Carstensen, L.L. (2010). Social and emotional aging. Annual Review of Psychology, 61, 383-409.

Coleman, P.G., Philp, I., \& Mullee, M. A. (1995). Does the use of the Geriatric Depression Scale make redundant the need for separate measures of well-being on geriatrics wards? Age and Ageing, 24(5), 416-420.

Djernes, J.K. (2006). Prevalence and predictors of depression in populations of elderly: A review. Acta Psychiatrica Scandinavica, 113(5), 372-387.

Fergusson, D.M., Horwood, L.J., \& Boden, J.M. (2011). Structural equation modeling of repeated retrospective reports of childhood maltreatment. International Journal of Methods in Psychiatric Research, 20(2), 93-104. doi:10.1002/ mpr.337 
Furrer, M., Heiniger, K., Huonker, T., Jenzer, S., \& Praz, A.-F. (Eds.). (2014). Fürsorge und Zwang: Fremdplatzierung von Kindern und Jugendlichen in der Schweiz 1850-1980 [Care and restraint: Foreign placement of children in adolescents in Switzerland Basel: 1850-1980]. Basel: Schwabe.

Fydrich, T., Sommer, G., Menzel, U., \& Höll, B. (1987). Fragebogen zur Sozialen Unterstützung (Kurzform) [Social Support Questionnaire (short form)]. Zeitschrift für Klinische Psychologie, 16, 434-436.

Fydrich, T., Sommer, G., Tydecks, S., \& Brähler, E. (2009). Fragebogen zur sozialen Unterstützung (F-SozU): Normierung der Kurzform (K-14) [Social Support Questionnaire (FSozU): Standardization of short form (K-14)]. Zeitschrift für Medizinische Psychologie, 18(1), 43-48.

Graham, J.W. (2003). Adding missing-data-relevant-variables to FIML-based structural equation models. Structural Equation Modeling, 10(1), 80-100. doi:10.1207/S15328007SEM 1001_4

Graham, J.W. (2009). Missing data analysis: Making it work in the real world. Annual Review of Psychology, 60, 549-576. doi:10.1146/annurev psych. 58.110405 .085530

Koenen, K.C., Stellman, J.M., Stellman, S.D., \& Sommer, J.F.J. (2003). Risk factors for course of posttraumatic stress disorder among Vietnam veterans: A 14-year follow-up of American legionnaires. Journal of Consulting and Clinical Psychology, 71(6), 980-986. doi:10.1037/0022006X.71.6.980

Kuhlman, K.R., Maercker, A., Bachem, R., Simmen-Janevska, K., \& Burri, A. (2013). Developmental and contextual factors in the role of severe childhood trauma in geriatric depression: The sample case of former indentured child laborers. Child Abuse and Neglect, 37(11), 969-978. doi:10.1016/j.chiabu.2013.04.013

Landau, R., \& Litwin, H. (2000). The effects of extreme early stress in very old age. Journal of Traumatic Stress, 13(3), 473-487.

Leuenberger, M., \& Seglias, L. (Eds.). (2008). Versorgt und vergessen: Ehemalige Verdingkinder erzählen [Supplied and forgotten: Former indentured child labourers tell]. Zürich: Rotpunkt.

Loke, S.C., Abdullah, S.S., Chai, S.T., Hamid, T.A., \& Yahaya, N. (2011). Assessment of factors influencing morale in the elderly. PloS One, 6(1), e16490.

Lucas, R.E., \& Donnellan, M.B. (2012). Estimating the reliability of single-item life satisfaction measures: Results from four national panel studies. Social Indicators Research, 105, $323-331$.

Lueger-Schuster, B., Kantor, V., Weindl, D., Knefel, M., Moy, Y., Butollo, A., ... Glück, T. (2014). Institutional abuse of children in the Austrian Catholic Church: Types of abuse and impact on adult survivors' current mental health. Child Abuse and Neglect, 38(1), 52-64.

Maercker, A., \& Horn, A.B. (2013). A socio-interpersonal perspective on PTSD: The case for environments and interpersonal processes. Clinical Psychology and Psychotherapy, 20 (6), 465-481. doi:10.1002/cpp.1805

Maercker, A., Krammer, S., \& Simmen-Janevska, K. (2014). Psychische Folgestörungen der Verdingung im Alter [Psychological sequelae of intendured child labour in old age]. In M. Furrer, K. Heininger, T. Huonker, S. Jenzer, \& A. Praz (Eds.), Fremdplatzierung von Kindern und Jugendlichen in der Schweiz 1850-1980 [Placement of children and adolescents in Switzerland 1850-1980] (pp. 373-385). Basel: Schwabe.

Maercker, A., \& Müller, J. (2004). Social acknowledgment as a victim or survivor: A scale to measure a recovery factor of PTSD. Journal of Traumatic Stress, 17(4), 345-351. doi:10.1023/B:JOTS.0000038484.15488.3d

Masten, A.S., \& Powell, J.L. (2003). A resiliency framework for research, policy and practice. In S.S. Luthar (Ed.), Resilience and vulnerability. Adaptation in the context of construction of a questionnaire for the assessment of disclosure of traumatic childhood adversities (pp. 1-29). Cambridge: Cambridge University Press.

Müller, J., \& Maercker, A. (2006). Disclosure und wahrgenommene gesellschaftliche Wertschätzung als Opfer als Prädiktoren von PTB bei Kriminalitätsopfern [Disclosure and perceived acknowledgement as a victim as predictors of PTB in crime victims]. Zeitschrift fuir Klinische Psychologie und Psychotherapie, 35(1), 49-58. doi:10.1026/16163443.35.1.49

Müller, J., Beauducel, A., Raschka, J., \& Maercker, A. (2000). Kommunikationsverhaltennach politischer Haft in der DDR Entwicklung eines Fragebogens zum Offenlegen der Traumaerfahrungen [Communication behavior after political imprisonment - experiences]. Zeitschrift für Politische Psychologie, 4, 413-427.

Mueller, J., Moergeli, H., \& Maercker, A. (2008). Disclosure and social acknowledgement as predictors of recovery from posttraumatic stress: A longitudinal study in crime victims. The Canadian Journal of Psychiatry, 53(3), 160-168.

Muthen, L.K., \& Muthen, B.O. (1998-2014). MPlus user's guide (7th ed.). Los Angeles, CA: Muthen \& Muthen.

Pietrzak, R.H., \& Cook, J.M. (2013). Psychological resilience in older U.S. veterans: Results from the national health and resilience in veterans study. Depression and Anxiety, 30(5), 432-443. doi:10.1002/da.22083

Schermelleh-Engel, K., Moosbrugger, H., \& Müller, H. (2003). Evaluating the fit of structural equation models: Tests of significance and descriptive goodness-of-fit measures. Methods of Psychological Research, 8(2), 23-74.

Schnurr, P.P., Spiro III, A., Vielhauer, M.J., Findler, M.N., \& Hamblen, J.L. (2002). Trauma in the lives of older men: Findings from the Normative Aging Study. Journal of Clinical Geropsychology, 8(3), 175-187.

Schoch, J., Tuggener, H., \& Wehrli, D. (1989). Aufwachsen ohne Eltern. Zur ausserfamiliären Erziehung in der deutschsprachigen Schweiz [Growing up without parents: On extrafamilial upbringing in Switzerland]. Zürich: Chronos.

Scholz, U., Gutierrez Dona, B., Sud, S., \& Schwarzer, R. (2002). Is general self-efficacy a universal construct? Psychometric findings from 25 countries. European Journal of Psychological Assessment, 18, 242-251

Sheikh, J.I., \& Yesavage, J.A. (1986). Geriatric Depression Scale (GDS): Recent evidence and development of a shorter version. Clinical Gerontologist: The Journal of Aging and Mental Health, 5(1-2), 165-173.

Simmen-Janevska, K., Brandstatter, V., \& Maercker, A. (2012). The overlooked relationship between motivational abilities and posttraumatic stress: A review. European Journal of Psychotraumatology, 3, 1-19. doi:10.3402/ejpt.v3i0.18560

Smyth, J.M., Pennebaker, J.W., \& Arigo, D. (2012). What are the health effects of disclosure? In A. Baum, T.A. Revenson, \& J.E. Singer (Eds.), Handbook of health psychology (pp. 175-205). New York, NY: Psychology Press.

Southwick, S.M., Litz, B.T., Charney, D., \& Friedman, M.J. (Eds.). (2011). Resilience and mental health: Challenges across the lifespan. Cambridge: Cambridge University Press.

Tietjen, G.E., Brandes, J.L., Peterlin, B.L., Eloff, A., Dafer, R. M., Stein, M.R., ... Khuder, S.A. (2010). Childhood maltreatment and migraine (part I). Prevalence and adult revictimization: A multicenter headache clinic survey. Headache, $50(1), 20-31$.

Tran, U.S., Glück, T.M., \& Lueger-Schuster, B. (2013). Influence of personal and environmental factors on mental health in a sample of Austrian survivors of World War II with regard to PTSD: Is it resilience? BMC Psychiatry, 13(1), 47.

Ullman, S.E. (2011). Is disclosure of sexual trauma as helpful? Comparing experimental laboratory versus field study results. Journal of Aggression, Maltreatment and Trauma, $20(2), 148-162$. 
Ungar, M. (2011). The social ecology of resilience: Addressing contextual and cultural ambiguity of a nascent construct. American Journal of Orthopsychiatry, 81(1), 1-17. doi:10.1111/j.1939-0025.2010.01067.x

Ware Jr, J.E., Kosinski, M., \& Keller, S.D. (1996). A 12 -item ShortForm Health Survey: Construction of scales and preliminary tests of reliability and validity. Medical Care, 34(3), 220-233.

Wingenfeld, K., Spitzer, C., Mensebach, C., Grabe, H.J., Hill, A., Gast, U., ... Driessen, M. (2010). Die deutsche Version des Childhood Trauma Questionnaire (CTQ): Erste Befunde $\mathrm{zu}$ den psychometrischen Kennwerten [The German version of the CTQ: First results on psychometric parameters]. Psychotherapie.Psychosomatik Medizinische Psychologie, 60 (11), 442-450.

Wittchen, H.U., Lachner, G., Wunderlich, U., \& Pfister, H. (1998). Test-retest reliability of the computerized DSM-IV version of the Munich-Composite International Diagnostic
Interview (M-CIDI). Social Psychiatry and Psychiatric Epidemiology, 33(11), 568-578.

Wolfe, D.A., Jaffe, P.G., Jette, J.L., \& Poisson, S.E. (2003). The impact of child abuse in community institutions and organizations: Advancing professional and scientific understanding. Clinical Psychology: Science and Practice, 10(2), 179-191. doi:10.1093/clipsy.bpg021

Yohannes, A.M., Dodd, M., Morris, J., \& Webb, K. (2011). Reliability and validity of a single item measure of quality of life scale for adult patients with cystic fibrosis. Health and Quality of Life Outcomes, 9(1), 1-8.

Zaudig, M., Mittelhammer, J., Hiller, W., Pauls, A., Thora, C., Morinigo, A., \& Mombour, W. (1991). SIDAM - a structured interview for the diagnosis of dementia of the Alzheimer type, multi-infarct dementia and dementias of other aetiology according to ICD-10 and DSM-III-R. Psychological Medicine, 21, 225-236. 